International Journal of Instruction e-ISSN: 1308-1470 • www.e-iji.net

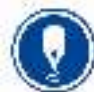

January $2021 \bullet$ Vol.14, No.1

p-ISSN: 1694-609X

pp. 631-646

Article submission code:

20200321055356
Received: 21/03/2019

Revision: 17/07/2020
Accepted: 09/08/2020

OnlineFirst:31/10/2020

\title{
Moderating Effect of Thai Teachers' Perspective on the Relationship between Teaching Perspectives, Students' Engagement
}

\section{Hareesol Khun-Inkeeree}

Dr., School of Languages and General Education, Walailak University, Thailand, sol.khun75@gmail.com

\section{Luckhana Pimjan}

Asst. Prof., corresponding author, School of Languages and General Education, Walailak University, Thailand, pluckhan@wu.ac.th

\section{Ayotunde Adetola Adelaja}

School of Business Management, Universiti Utara Malaysia, Malaysia, ayoadelaja@live.com

Studies on students' engagement in the academic field seem to be widely explored. Similar investigations at the primary education level remain at its infancy stage. Especially in Thailand where the literacy level is low. To achieve the study objectives, teachers at primary schools in Nakhon Si Thammarat province of Thailand were randomly selected and surveyed. The data retrieved were analyzed using structural equation modelling. The result reveals an insignificant relationship between teaching perspective and students' engagement. However, the teaching perspective inventory has a negative significant moderating effect. The research implication to education policymakers was extensively discussed.

Keywords: moderating, Thai teacher, teachers' perspective, teaching perspectives, students' engagement

\section{INTRODUCTION}

Educated individuals in society play a significant role in ensuring environmental sustainability, creativity, and innovation, peace, and economic stability. They also advocate for gender equality good governance as well as ensuring individual and national progress (Aleixo, Leal \& Azeiteiro, 2018; Novo-Corti, Badea Tirca \& Aceleanu, 2018; Woolman, 2001). To achieve the significance of education, students must be carried along and connected with the teaching instructions, that is, the students must be engaged with classroom activities. Hence, students' engagement had received significant interest from educators, scholars, and practitioners (Tai, Bellingham, Lang \& Dawson, 2019).

Students' engagement has therefore been argued to be a significant meiasure of success of teachers and the program taught (Coates, 2005; Novo-Corti et al., 2018; Tai et al.,

Citation: Khun-Inkeeree, H., Pimjan, L., \& Adelaja, A. A. (2021). Moderating Effect of Thai Teachers' Perspective on the Relationship between Teaching Perspectives, Students' Engagement. International Journal of Instruction, 14(1), 631-646. https://doi.org/10.29333/iji.2021.14138a 
2019) as well as a measure of quality assurance in education, learning output and academic performance (Abubakar \& Itse, 2017; Coates, 2005; Robinson, 2013). In light of this, authors such as Doerr and English (2006), Novo-Corti et al., (2018), Woolman (2001), Sinatra, Heddy and Lombardi (2015) described students' engagement in diverse ways. Ashwin and McVitty (2015) argue students' engagement can be solidly defined. However, the concept received poor definition due to scholars' laziness leading to less critical view and focus points of the definition's ambiguity. Conversely, a recent study by Vytasek, Patzak, and Winne (2020) recommends the need to redefine the concept, its observations, and quantification. Despite the disagreement on the definition of students' engagement, there is arguably unanimous agreement on its dimension, namely psychological, cognitive and emotion (Parsons \& Taylor, 2011; Pratt, 2002; Sinatra et al., 2015).

Evidence from earlier studies reveal factors not limited to, teaching perspective, teachers' emotion, teachers' efficacy, peer group interaction, school achievement, learning assessment, and pedagogical practices were identified to influence students' engagement among students of higher education institutions (Exeter, Ameratunga, Ratima, Morton, Dickson, Hsu \& Jackson, 2010; Pietarinen, Soini \& Pyhältö, 2014; Vytasek et al., 2020). From these numerous factors, this study explored the significant contribution of teaching perspectives on students' engagement. The logic behind these lies in the conclusions presented in the study of Exeter et al. (2010) and Vollet, Kindermann, and Skinner (2017).

\section{Problem Statement}

Further insights into the available earlier studies reveal that a larger percentage of these studies are conducted in the context of higher education institutions (Connelly \& Zheng, 2003; Exeter et al., 2010; Farooq, Chaudhry, Shafiq \& Berhanu, 2011; Vytasek et al., 2020). While studies from other education levels specifically, studies investigating students' engagement, teaching perspectives and teaching perspective inventory in the context of primary schools remain at its infancy stage.

Meanwhile, primary education is the fundamental and the earliest stage of the education system whereby teachers teach pupils basic reading, speaking and writing skills that make them thrive in life (Global Partnership for Education 'GPE', 2019; Rivers, 2018). At this early stage, the pupils assimilate and imitates virtually every character of the teachers teaching them in schools. Teachers re-culture these children into a new way of thinking 'cognitive process' therefore, corresponding to what Pratt (2002) posits as an apprentice perspective. This has both, directly and indirectly, translates to teaching perspectives and education quality (Bonk, Appleman \& Hay, 1996; Karagiorgi \& Symeou, 2005). The radical transformation and the ability to reproduce these characters by these children influence the teaching perspective of the teachers in the mind of the children's parents (Temple, Ogle, Crawford \& Freppon, 2017). Conducting this study in the context of primary school is paramount. There are indications that, although there is increased access to primary in Thailand, the literacy rate is still below average comparing it to their neighboring ASEAN states (Rachel \& Stefan, 2018). Thus, the need to improve Thailand primary education is tantamount. 
Besides, there are indications that the relationship between teaching perspective is enhanced the elements of teaching perspectives inventory (Reeve, Jang, Carrell, Jeon \& Barch, 2004; Lo \& Hyland, 2007; Reeve \& Shin, 2019; Roorda et al., 2011) therefore, this study in the context of primary education, examine the moderating effect of teachers' perspective inventory on the relationship between teaching perspective and engaging primary school students.

\section{REVIEW OF LITERATURE}

\section{Student Engagement}

Students' engagement has been one of the emerging researches in the educational field. Described as the process of connecting students to the teaching and learning process via emotional, psychological and cognition (Pratt, 2002). Investigations on how to enhance or engage students academically had been thoroughly investigated (Ashwin \& McVitty, 2015; Robinson, 2013; Parsons \& Taylor, 2011; Zepke \& Leach, 2010). This, according to Boud and Molloy (2013) is achieved through learners' feedback on teaching perspective.

Examining the construct students' engagement has been one of the fundamental works in achieving quality assurance, desired learning outcomes and academic performance (Abubakar \& Itse, 2017; Çapri, Gündüz \& Akbay, 2017; Carmona-Halty, Schaufeli, \& Salanova, 2019; Coates, 2005; Robinson, 2013). This can be achieved by enhancing the students' emotional, psychological and cognitive engagement (Carmona-Halty et al., 2019; Pietarinen, Soini \& Pyhältö, 2014). Besides, the attention of scholars had also been drifted from disengaged students to engage students by realigning the course contents to the needed knowledge in the society (Kezar \& Rhoads, 2001; Parsons \& Taylor, 2011). Hence, over the years, there have been significant efforts to untangle the complex relationship between factors that might enhance students' engagement and the actual engagement that translates to desired results.

In the study of Coates (2005), there are theoretical indications that students' engagement significantly predicts quality assurance in education. While Pietarinen et al. (2014) argue that the emotions of students (cognitive and social) regulate their cognition that in turn influence the interaction between peers and academic achievement. This supports the findings from scholars such as (Persons and Taylor, 2011). As a learner, the key role includes learning and giving feedback on their perception towards the teacher and judge the relevance of the subject learned to society (Boud \& Molloy, 2013).

Considering the factors that can enhance students' engagement, teaching perspectives which might be in the form of teachers' autonomy, teachers' attitude, emotions, the strategy employed in teaching styles, peer influence, students' satisfaction, and course connections were argued to significantly influence students' engagement inside and outside the classrooms (Guillén \& Martínez-Alvarado, 2014; Sulaiman, \& Zahoni, 2016; Pietarinen et al., 2014; Reeve, Jang, Carrell, Jeon \& Barch, 2004).

As evidence, students' engagement, teaching perspectives, and teachers' training and development had been extensively researched, however, in the context of higher education or adult education while less attention is formally given to student 
engagement among primary school students (See: Connelly \& Zheng, 2003; Farooq et al. 2011; Rivers, 2018; Temple et al., 2017).

\section{Teaching Perspectives and Students Engagement}

Teaching perspectives in terms of attitudes and emotions, behaviors and autonomy they exhibit while teaching students predicts the level of students' interactions or engagements (Assor, Kaplan \& Roth, 2002; Hagenauer, Hascher \& Volet, 2015). This can range from positive to negative or high to a low level of engagement (Roorda, Koomen, Spilt \& Oort, (2011). Evidence from the available pieces of the literature reveals different effects of teaching perspectives on students' engagement levels. Starting with the study of Assor et al. (2002) where the authors argue that both children and adolescents investigated can perceive teachers' autonomy behavior thus, translating to students' emotions and engagement. Therefore, the authors conclude that children need a certain degree of autonomy to encourage engagement. Indirectly, engaging teaching perspective inventory, Doerr and English (2006) concludes a significant influence of teaching perspectives on students' ability to engage in mathematics class. Also, Roorda et al. (2011) employing a meta-analytic approach argue that teaching perspectives differ in levels of education. According to the study of Roorda et al. (2011), a negative relationship was found in primary education while among secondary school students, the result found tends to be positive.

A recent study by Reeve and Shin (2019) argues that adopting autonomy support teaching style of teaching significantly enhances positive students' engagement. On the account of Lo and Hyland (2007), different teaching style creates different engagement level amongst students. Findings from their study reveal that motivating established students lowers their performance while the same style improve the performance of underachieving students.

Despite this, there are also indications that the relationship is moderated by the style of teaching adopted (Roorda et al., 2011). With this, the following subsection explores the relationship between teaching style known as teaching perspective inventory (Pratt, 2002) and its moderating effects on the relationship between teaching perspective and students' engagement.

\section{Teaching Perspective Inventory (TPI)}

Efforts to develop a more realistic and sustainable teaching practice that translates to desired results lead to the creation of TPI. The TPI approach ever since its creation, it had been used in different ways. For example, TPI is employed to develop teaching philosophies, identify reasonable variations on excellence in teaching and engendering teaching discussions. Besides, the TPI tools gained wider acceptance because it allows measuring teachers' intention, action as well as get feedback (Collins \& Pratt, 2011; Pratt \& Collins, 2002) more importantly, TPI had been adopted in numerous empirical studies, examples of which are not limited to the study of Robertson, Fowler, and Juve (2017), Pratt and Collins (2000).

Teaching perspective inventory (TPI) is divided into five different but interrelated teaching approaches.These dimensions are transmission, apprenticeship, developmental, 
nurturing and social reform (Pratt, 2002; Pratt \& Collins, 2020). These five classifications or perspectives as posited by Pratt and Collins (2002) are exclusive and that, no teacher has it all. As presented, the transmission dimension relates to a teaching style that requires a significant obligation to the subject being taught. Thus, presenting the subject as possible is the keynote in this regard. While apprenticeship teaching strategy entails teaching via socializing the students into new behavioral norms and ways of getting things done in a different dimension. This is more of a guidance and prediction of what students can achieve and among peers. So, the developmental approach implies a planning style of teaching that must be planned and effected from the learner's point of view. An example includes the use of effective questions to challenge the stance of learners. The nurturing style of teaching argues that effective teaching assumes long term efforts and persistence to achieve the desired outcomes from the heart and not the head of the student. The last point is social reform. A teaching style that seeks to have a significant change in societal life.

Studies such as Deggs, Machtmes, and Johnson (2008) and Pratt (2002), Roorda et al. (2011) investigates the occurrence of these different teaching styles. They argue that indeed there is a significant difference among the respondents. Nevertheless, Deggs et al. (2002) argue that apprenticeship is the most dominant teaching style. Also, Hudley, Daoud, Polanco, Wright-Castro and Hershberg (2003) argue that the relationship between teaching perspective and students' engagement is moderated by the supports received.

\section{Purpose and Objectives of Study}

From the pieces of the reviewed literature, there are clear evidence that a significant relationship exists between teaching perspectives and students' engagement. Considering this, the first hypothesis and teaching perspective and students' engagement is moderated given two hypotheses. This study was formulated three hypothesis posits that:

\section{Research hypotheses}

H1: There is a significant relationship between teaching perspective and students' engagement.

$\mathrm{H} 2$ : There is a significant relationship between Teaching perspective inventory and students' engagement.

H3: TPI significantly moderates the relationship between teaching perspective and students' engagement.

\section{METHOD}

\section{Sampling}

These samples used in this study were chosen because extant literature about students' engagement at the higher education level is so enormous (Connelly \& Zheng, 2003; Farooq et al. 2011; Rivers, 2018; Temple et al., 2017). To achieve the objectives of this study, a sample of 200 primary school teachers was randomly selected from the teachers teaching primary schools at Nakhon Si Thammarat provinces in Thailand. 


\section{Measurement of Construct}

All the adapted items in this study were measured using a 5-point Likert scale ranging from 1 = Strongly Disagree (SD); 2 = Disagree (D); $3=$ Neutral (N); 4 Agree (A); 5 = Strongly Agree (SA).

\section{Students' Engagement}

To measure students' engagement in this study, the concept is defined around three dimensions, namely: psychology, emotion and cognitive interactions with teachers and peers during classroom experience. Overall, 19 items measuring the three dimensions were adapted from the Utrecht Work 70 Engagement Scale (UWES). 7 items were used in measuring cognitive engagement. The remaining 12 items were used to measure psychological and emotional engagement. These UWES scales has been globally accepted as scales adapted and validated to measure engagement in several contexts, not limited to employees, students and workers (Çapri, Gündüz \& Akbay, 2017; CarmonaHalty, Schaufeli, \& Salanova, 2019; Guillén \& Martínez-Alvarado, 2014; Sulaiman, \& Zahoni, 2016).

\section{Teaching Perspective}

The items used in measuring teaching perspectives in this study were adapted from the studies of Assor et al. (2002), Hagenauer et al. (2015), Lo and Hyland (2007) and Reeve and Shin (2019). The items cover various teaching perspectives such as the influence of training on teaching styles examples of which include attitudes and emotions, behaviors and autonomy. In total, ten (10) items instruments were adapted and used in this study.

\section{Teaching perspective inventory}

To measure teaching perspective inventory, items were adapted from the study of Assor et al. (2002), Doerr and English (2006), Roorda et al. (2011), Pratt and Collins (2000) and Williams and Evans-Winters (2005). The items adapted followed the five dimensions of teaching perspective inventory. Not only this, but the five dimensions of teaching perspective inventory also revolve around the teachers' actions, intention, and beliefs as showed link (https://drive.google.com/file/d/15fVk6odrNDL0zmOUFAklbZ5-zfhkukJ/view?usp=sharing).

\section{Data Analysis}

\section{Missing values}

The researchers examined the data for any missing values. The analysis in this regard [resents that some data are missing. However, were not replaced. This is because the missing data are less than 5\%. According to the study of Garson (2012), missing data of less than 5\% have no significant difference in the analysis output, so the authors are said to be at liberty of not replacing the missing values. Considering this, the missing values are not being replaced.

\section{Normality and outliers}

Although the Statistical tool PLS-SEM is a non-parametric tool used in this study do not warrant checking of outliers, yet, scholars encouraged the 
The three dimensions of the DV were used in checking for an unusual pattern in this study so that normality of the data can be achieved, and the statistical approach can fulfill the conditions for parametric testing (Hair, Ringle, \& Sarstedt, 2013) Considering this, a total response of 20 items were deleted from 196 responses. Thus, the authors are left with 176 responses. The outliers and normality testing are achieved using skewness and Kurtosis and boxplot. The report before and after outlier deletions were presented in the table and figure below.

Table 1

Data Normality Before and After Removing Outliers

\begin{tabular}{llllllllll}
\hline \multicolumn{4}{l}{ Before Removal of Outliers } & \multicolumn{5}{c}{ After Removing Outliers } \\
\hline S/N & Variable & Mean & Median & Skewness & Kurtosis & Mean & Median & Skewness & Kurtosis \\
1 & CE & 4.26 & 4.40 & -1.98 & 6.15 & 4.44 & 4.47 & -.50 & -.29 \\
2 & EE & 4.31 & 4.53 & -2.58 & 6.68 & 4.53 & 4.60 & -.48 & -.79 \\
3 & PC & 4.17 & 4.31 & -2.04 & 4.97 & 4.36 & 4.34 & -.09 & -.73 \\
\hline
\end{tabular}

As presented in table 1 , the skewness and kurtosis values before removing the outliers are greater than absolute 1 and 3 ( \pm 1 for skewness; \pm 3 for kurtosis). Meanwhile, after removing data points presented to be outliers by the statistical software used, the skewness and kurtosis values are within the range of absolute \pm 1 and \pm 3 .

\section{FINDINGS}

\section{Demographic Data Analysis}

Table 2

Present the Analysis Data Demography

\begin{tabular}{llll}
\hline Demographic Variable & Category & Frequency & Percentage \\
\hline Gender & Male & 50 & 29.40 \\
& Female & 120 & 70.60 \\
Age & Less than 30 & 60 & 35.30 \\
& $31-35$ & 75 & 44.12 \\
Level of Education & Above 35 & 35 & 20.58 \\
& Degree & 102 & 38.80 \\
\multirow{3}{*}{ Marital Status } & Master & 66 & 60.00 \\
& PhD & 2 & 1.20 \\
Salary & Single & 87 & 51.20 \\
& Married & 79 & 46.50 \\
& Divorce & 4 & 1.80 \\
& $20,000-25,000$ & 123 & 72.35 \\
& $25,001-30,000$ & 22 & 12.90 \\
& Above 30,000 & 25 & 14.70 \\
\hline
\end{tabular}

The data present that most of the respondents are female having $70.60 \%$ (120) while the other $29.40 \%$ (50) respondents are male counterparts. Besides, most respondents fall within the age-group of 31-35 having $44.12 \%$ (75) respondents, followed by age-group less than 30 having $38.80 \%$ (66) and the last group is above 35 having $20.58 \%$ (35) respondents respectively.

Furthermore, it was observed that most of the respondents have at least abachelor's degree, followed by a master's degree and Ph.D. degree certificate having 60\% (102), $38.80 \%$ (66) and $1.2 \%$ (2) respondents respectively. Also, most of the sample surveyed are single followed by the married class and those that are divorce having $51.20 \%$ (87), 
$79 \%, 46.50 \%$ (79) and $1.80 \%$ (4). Majority of the respondents reveal that they earn a monthly salary of within $20,000-25,000 \mathrm{~TB}$ while the least group said they earn above $30,000 \mathrm{~TB}$ followed by the group that claims they earn between 25,001 to $30,000 \mathrm{~TB}$ having $72.35 \%$ (123), $14.70 \%$ (25) and $12.90 \%$ (22).

\section{Inferential Statistics}

Using Smart PLS-SEM 3.2.9, the relationship between the constructs was observed. The nature of two of the three constructs investigated is a higher-order construct as such, reflective-reflective modeling in line with the proposition of Chin (1988) and Sarstedt, Hair, Cheah, Becker, and Ringle (2019) was employed. Besides, a disjoint two-stage approach was employed (Sarstedt et al., 2019) suing the indicators of the lower order construct leading directly to the Higher-order construct theoretically presented. Both the measurement model and the structural model were accessed and are presented below.

\section{Measurement Model}

Under the measurement model, each construct Average Variance Extracted (AVE), Cross Loadings (CL), Cronbach Alpha and Composite Reliability were accessed.

Discriminant Validity: is a very fundamental assessment needed to be conducted. doing this, the loadings must be greater than 0.6, AVE greater than 0.5, CR and CA must be 0.7 greater, HTMT criterion, that is, the inter-correlation between each construct must not be greater than 0.895 (Henseler, Ringle \& Sarstedt, 2015). Although, Hensler et al. (2015) kick against reporting of Fornell Larcker Criterion in favor of HTMT, yet, several scholars continue reporting such to measure items discriminant validity. Hence, this study also reports such.

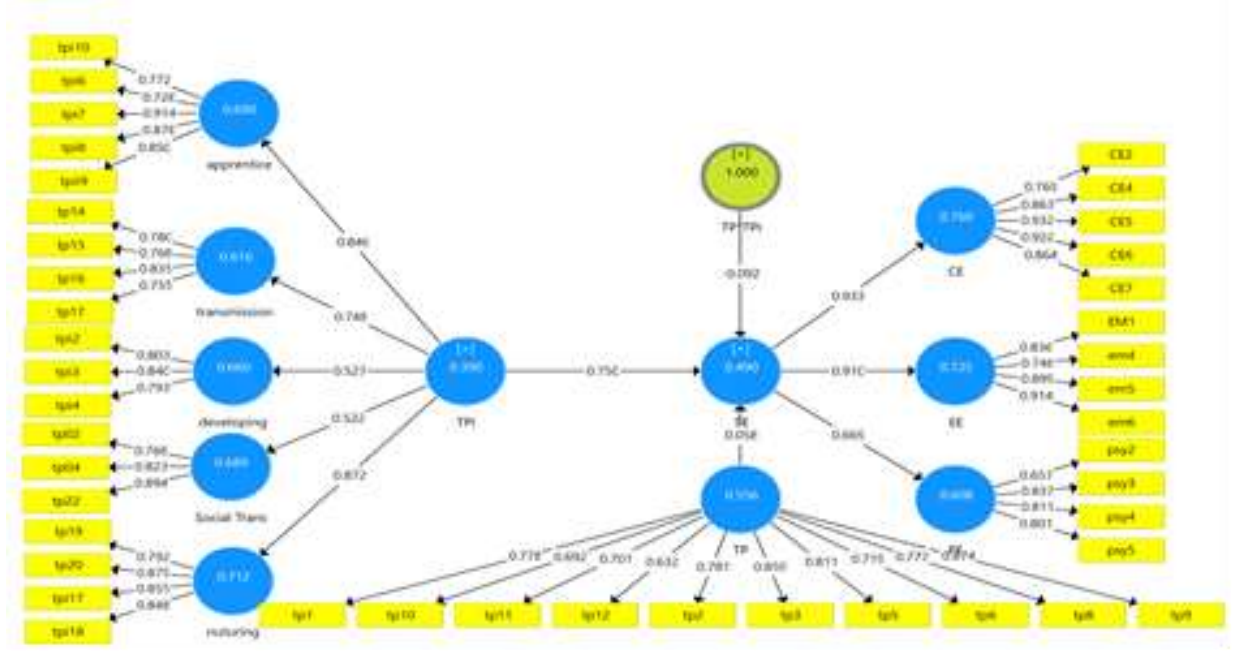

Diagram 1

Measurement Model 
The figure reveals that all the constructs fulfill the measurement model, therefore, the interpretations are presented in the table below.

Table 3

Convergent Validity

\begin{tabular}{|c|c|c|c|c|c|c|}
\hline Construct & Items & Items Loadings & Alpha & $\mathrm{CR}$ & AVE & Convergent Validity \\
\hline \multirow[t]{5}{*}{$\mathrm{CE}$} & CE2 & 0.769 & 0.92 & 0.94 & 0.76 & YES \\
\hline & CE4 & 0.863 & & & & \\
\hline & CE5 & 0.932 & & & & \\
\hline & CE6 & 0.922 & & & & \\
\hline & CE7 & 0.864 & & & & \\
\hline \multirow[t]{4}{*}{$\mathrm{EE}$} & EM1 & 0.836 & 0.872 & 0.913 & 0.725 & YES \\
\hline & EM4 & 0.746 & & & & \\
\hline & EM5 & 0.899 & & & & \\
\hline & EM6 & 0.914 & & & & \\
\hline \multirow[t]{4}{*}{ PE } & PSY2 & 0.657 & 0.786 & 0.86 & 0.608 & YES \\
\hline & PSY3 & 0.837 & & & & \\
\hline & PSY4 & 0.811 & & & & \\
\hline & PSY5 & 0.801 & & & & \\
\hline \multirow[t]{10}{*}{ TP } & TP1 & 0.778 & 0.91 & 0.925 & 0.556 & YES \\
\hline & TP2 & 0.692 & & & & \\
\hline & TP3 & 0.701 & & & & \\
\hline & TP4 & 0.632 & & & & \\
\hline & TP5 & 0.781 & & & & \\
\hline & TP6 & 0.859 & & & & \\
\hline & TP7 & 0.811 & & & & \\
\hline & TP8 & 0.719 & & & & \\
\hline & TP9 & 0.777 & & & & \\
\hline & TP10 & 0.674 & & & & \\
\hline \multirow[t]{5}{*}{ Apprentice } & TPI6 & 0.726 & 0.885 & 0.917 & 0.69 & YES \\
\hline & TPI7 & 0.914 & & & & \\
\hline & TPI8 & 0.876 & & & & \\
\hline & TPI9 & 0.850 & & & & \\
\hline & TPI10 & 0.772 & & & & \\
\hline \multirow{3}{*}{ Developing } & TP2 & 0.803 & 0.745 & 0.853 & 0.66 & YES \\
\hline & TP3 & 0.840 & & & & \\
\hline & TP4 & 0.793 & & & & \\
\hline \multirow{4}{*}{ Nurturing } & TP17 & 0.792 & 0.865 & 0.908 & 0.712 & YES \\
\hline & TP18 & 0.879 & & & & \\
\hline & TP19 & 0.855 & & & & \\
\hline & TP20 & 0.848 & & & & \\
\hline \multirow[t]{4}{*}{ Transmission } & TP14 & 0.780 & 0.793 & 0.865 & 0.616 & YES \\
\hline & TP15 & 0.768 & & & & \\
\hline & TP16 & 0.835 & & & & \\
\hline & TP17 & 0.755 & & & & \\
\hline \multirow[t]{3}{*}{ Social Trans } & ТP02 & 0.768 & 0.781 & 0.869 & 0.689 & YES \\
\hline & ТР04 & 0.823 & & & & \\
\hline & TP22 & 0.894 & & & & \\
\hline
\end{tabular}

N/B: AVE for the higher order construct students' engagement (SE) and Teaching Perspective Inventory (TPI) were calculated using the formula presented below:

$A V E=\sum_{i=1}^{M} l_{1}^{2} / M$ 
Where $l_{1}$ represent the loading of lower construct measured with $\mathrm{M}$ lower-order components.

$i$ ranges from 1 to $M$

Therefore, $\mathrm{AVE}_{\mathrm{TPI}}=\frac{.846^{2}+.748^{2}+.527^{2}+.522^{2}+.872^{2}}{5}=0.517$

$\mathrm{AVE}_{\mathrm{SE}}=\frac{.933^{2}+.910^{2}+.669^{2}}{3}=0.715$

With the AVE of TPI and SE greater than 0.5, it is therefore concluded that the measurement model criterion for higher-order construct is fulfilled as proposed by Hair et al. (2010) and Hensler et al. (2015).

Construct Validity: The alpha and the composite reliability, value from the table above are greater than the minimum required 0.7 as prescribed in the study of Hair et al (2010). Hence, the instruments used are said to be reliable.

Table 4

HTMT (Items inter-correlations)

\begin{tabular}{|c|c|c|c|c|c|c|c|c|}
\hline Construct & $\mathrm{CE}$ & $\mathrm{EE}$ & $\mathrm{PE}$ & $\begin{array}{l}\text { Social } \\
\text { Trans }\end{array}$ & $\mathrm{TP}$ & Apprentice & Developing & $\begin{array}{c}\text { Nurturin } \\
\mathrm{g}\end{array}$ \\
\hline $\mathrm{EE}$ & 0.869 & & & & & & & \\
\hline PE & 0.519 & 0.542 & & & & & & \\
\hline Social Trans & 0.461 & 0.35 & 0.244 & & & & & \\
\hline $\mathrm{TP}$ & 0.775 & 0.683 & 0.494 & 0.653 & & & & \\
\hline Apprentice & 0.833 & 0.802 & 0.329 & 0.549 & 0.785 & & & \\
\hline Developing & 0.469 & 0.435 & 0.895 & 0.098 & 0.437 & 0.318 & & \\
\hline Nurturing & 0.724 & 0.755 & 0.723 & 0.306 & 0.829 & 0.735 & 0.733 & \\
\hline Transmission & 0.541 & 0.636 & 0.473 & 0.667 & 0.766 & 0.58 & 0.315 & 0.63 \\
\hline
\end{tabular}

Table 5

Fornell Larcker Criterion

\begin{tabular}{|c|c|c|c|c|c|c|c|c|c|}
\hline Construct & $\mathrm{CE}$ & $\mathrm{EE}$ & $\mathrm{PE}$ & ST & $\mathrm{TP}$ & App & Dev & Nurture & Trans \\
\hline $\mathrm{CE}$ & 0.872 & & & & & & & & \\
\hline $\mathrm{EE}$ & 0.783 & 0.851 & & & & & & & \\
\hline PE & 0.463 & 0.474 & 0.779 & & & & & & \\
\hline Social Trans & 0.422 & 0.317 & 0.083 & 0.83 & & & & & \\
\hline $\mathrm{TP}$ & 0.717 & 0.61 & 0.428 & $\begin{array}{c}0.57 \\
1\end{array}$ & 0.745 & & & & \\
\hline Apprentice & 0.753 & 0.708 & 0.285 & $\begin{array}{c}0.48 \\
5\end{array}$ & 0.705 & 0.83 & & & \\
\hline Dev & 0.385 & 0.356 & 0.693 & $\begin{array}{c}0.02 \\
8\end{array}$ & 0.366 & $\begin{array}{c}0.25 \\
7\end{array}$ & 0.812 & & \\
\hline Nurture & 0.647 & 0.663 & 0.6 & $\begin{array}{c}0.27 \\
6\end{array}$ & 0.744 & $\begin{array}{c}0.64 \\
9\end{array}$ & 0.586 & 0.844 & \\
\hline Trans & 0.462 & 0.528 & 0.396 & $\begin{array}{c}0.53 \\
9\end{array}$ & 0.652 & $\begin{array}{c}0.48 \\
5\end{array}$ & 0.247 & 0.53 & 0.785 \\
\hline
\end{tabular}

Note: Diagonal elements are the square root of the AVE of the reflective scales while the diagonals are the correlations between constructs

Using HTMT and Fornel Larcker criterion to access the model discriminant validity, it is observed that the HTMT value (mean value of the item correlations) did not exceed 
0.895 as posited by Hair et al. (2010) and Sarstedt et al. (2019). Similarly, the Fornel Larcker criterion was fulfilled.

\section{Hypothesis Testing}

The researchers access the structural model between exogenous and the endogenous constructs, that is, TPI, TP, and SE. also the moderating effect of TPI on TP and SE is examined.

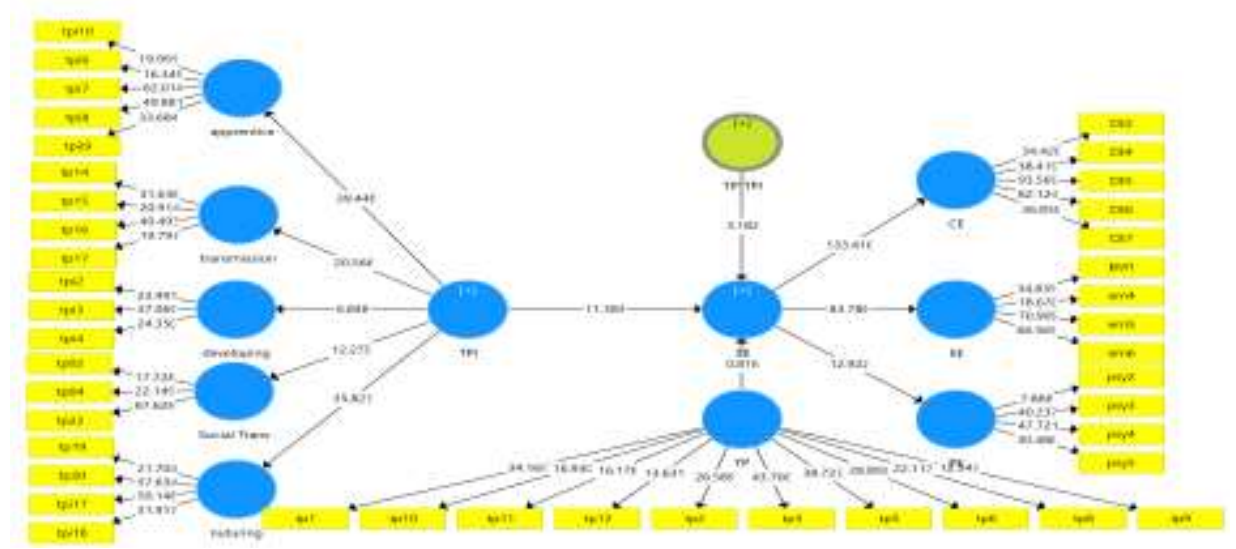

Diagram 2

Testing the Structural Relationship

Table 6

Testing the Structural Relationship

\begin{tabular}{lllllll} 
Hypothesis & Relationship & $\beta$ & STDEV & T Stat & P Values & Result \\
\hline $\mathrm{H}_{1}$ & TP $>$ SE & 0.058 & 0.071 & 0.816 & 0.415 & Not Significant \\
$\mathrm{H}_{2}$ & TPI $>$ SE & 0.75 & 0.066 & 11.384 & 0.000 & Significant \\
$\mathrm{H}_{3}$ & TP*TPI - > SE & -0.092 & 0.029 & 3.182 & 0.001 & Significant \\
\hline
\end{tabular}

This table presents the result of the structural model. The table shows that the teachers' perspective has an insignificant relationship with students' engagement having $(\beta=$ $0.058, \mathrm{p}>0.05$ ). With this, $\mathrm{H}_{1}$ is not supported.

The relationship between TPI and SE was also analyzed. The result shows that TPI $(\beta=$ $0.75, \mathrm{p}<0.05)$ has a significant relationship on SE. considering this, $\mathrm{H}_{2}$ was supported.

Considering the moderating effect of TPI on the relationship between TP and SE. the result presents that TPI $(\beta=-0.092, \mathrm{p}<0.05)$ has a significant moderating effect on the relationship between TP and SE. However, this effect is negatively significant. Considering this, $\mathrm{H}_{3}$ was supported.

\section{DISCUSSION}

The research model reveals that the variables under investigation explain $70.3 \%$ that is, $\mathrm{r}^{2}=0.73$. The hypotheses findings reveal that there is an insignificant relationship between teaching perspective and students' engagement. This finding in this regard, 
align with findings of Lo and Hyland (2007) and Roorda et al. (2011) where they argue that different teaching style influences students' engagement. Conversely, the findings in this regard did not agree with the studies of Assor et al. (2002), Reeve and Shin (2019), and Doerr and English (2006) where a positive significant result between teachers' perspectives and students' were recorded. This implies that among the primary school teachers surveyed, they didn't believe their teaching perspectives were able to engage the primary school students to study. The observed result thus reveals the ongoing issue of low literacy level echoed by Rachel and Stefan (2018).

On the other hand, teaching perspective inventory reveals a significant relationship in enhancing students' engagement. While teaching perspective inventory plays the role of moderator to enhance students' engagement, the result presents a significant moderating effect. However, this relationship is negative.

Relating these findings to earlier studies and the reality in the research context, it thus reveals the significance of teaching perspectives such as teachers' attitude, behavior emotions, and autonomy that enhance students' emotional, cognitive and psychological engagement (Çapri et al., 2017; Carmona-Halty et al., 2019; Coates, 2005; Robinson, 2013). In the context of this study, the finding on the significance of teaching perspective in enhancing students' engagement corresponds to the conclusion of Roorda et al. (2011) concluding a no relationship in the context of primary school.

\section{Implication of Findings}

\section{Practical implication}

The findings of this study present the reality of Thailand's primary education from the lens of students' engagement. The insignificant result presents that there is a certain level of disengagement between the primary school teachers and the primary school students. Therefore, this can be one of the reasons why primary school students in Thailand are less performing when compared with students from neighboring ASEAN states.

\section{Theoretical implication}

The findings of this study present a novel approach to improving primary school students' engagement. The observations contribute not only to the body of knowledge in the Thailand context but to the literature on ways of enhancing students' engagement at the primary education level.

\section{Recommendation}

It is recommended by the authors of this study that, since teaching perspective is measured concerning perceived teachers' emotion, attitude, styles and employed, which according to Farooq et al. (2011), Rivers (2018) and Temple et al. (2017) is enhanced via subjecting the primary school teachers to adequate training that can teach them various teaching styles to handle and increase students' engagement. 


\section{CONCLUSION}

To enhance the literacy level among primary school students, this study investigates the relationship between teachers' perspective and students' engagement using teaching perspective inventory as a moderator in the relationship. The result reveals that among the teachers surveyed, teachers' perspectives have no significant relationship with students' engagement. However, with the moderating effect of teaching perspective inventory primary school students in Thailand can be positively engaged. The results in this regard imply that to successfully engage primary school students, the teachers must be familiar with different teaching styles namely apprentice, transmission, developing, social transformation, and nurturing. Teachers knowing these teaching styles can easily make them switch and implement any, or combines the styles that fit the demand of the pupils. By doing this, there is a higher chance that the primary school students will be engaged and this will solve the looming of low literacy issues in Thailand the context of this study and other places that are facing similar issues as addressed in this study.

Although this study reveals the literacy issue in Thailand primary schools, yet, the samples employed might not be true representatives of the entire primary schools population in Thailand because limited samples used. Thus, the result might be biased against generalizability purposes. It is therefore recommended that similar studies should be conducted with a bigger sample size, and as well, conducted in other Thailand provinces. The potential results from future studies in this study context cannot be ascertained to be the same. This is because of the homogeneity of the samples surveyed. Despite these limitations, the findings of this study cannot be undermined.

\section{REFERENCES}

Abubakar, Y., \& Itse, J. D. (2017). Students' engagement in relationship to academic performance. Journal of Education and Social Sciences, 8(1), 5-8.

Aleixo, A. M., Leal, S., \& Azeiteiro, U. M. (2018). Conceptualization of sustainable higher education institutions, roles, barriers, and challenges for sustainability: An exploratory study in Portugal. Journal of Cleaner Production, 172, 1664-1673.

Ashwin, P., \& McVitty, D. (2015). The meanings of student engagement: implications for policies and practices. In The European higher education area (pp. 343-359). Springer, Cham.

Assor, A., Kaplan, H., \& Roth, G. (2002). Choice is good, but relevance is excellent: Autonomy-enhancing and suppressing teacher behaviours predicting students' engagement in schoolwork. British Journal of Educational Psychology, 72(2), 261-278.

Bonk, C. J., Appleman, R., \& Hay, K. E. (1996). Electronic conferencing tools for student apprenticeship and perspective taking. Educational Technology, 36(5), 8-18.

Boud, D., \& Molloy, E. (2013). Rethinking models of feedback for learning: the challenge of design. Assessment \& Evaluation in higher education, 38(6), 698-712. 
Çapri, B., Gündüz, B., \& Akbay, S. E. (2017). Utrecht work engagement scale-student forms' (UWES-SF) adaptation to Turkish, validity and reliability studies, and the mediator role of work engagement between academic procrastination and academic responsibility. Educational Sciences: Theory and Practice, 17(2), 411-435.

Carmona-Halty, M. A., Schaufeli, W. B., \& Salanova, M. (2019). The Utrecht work engagement scale for students (UWES-9S): Factorial validity, reliability, and measurement invariance in a Chilean sample of undergraduate university students. Frontiers in Psychology, 10, 1017.

Coates, H. (2005). The value of student engagement for higher education quality assurance. Quality in Higher Education, 11(1), 25-36.

Collins, J. B., \& Pratt, D. D. (2011). The teaching perspectives inventory at 10 years and 100,000 respondents: Reliability and validity of a teacher self-report inventory. Adult Education Quarterly, 61(4), 358-375.

Connelly, R., \& Zheng, Z. (2003). Determinants of school enrollment and completion of 10 to 18-year olds in China. Economics of Education Review, 22(4), 379-388.

Deggs, D. M., Machtmes, K. L., \& Johnson, E. (2008). The significance of teaching perspectives among academic disciplines. College Teaching Meth \& Styles J., 4(8), 1-8.

Doerr, H. M., \& English, L. D. (2006). Middle grade teachers' learning through students' engagement with modeling tasks. J. of Math. Teacher Education, 9(1), 5-32.

Exeter, D. J., Ameratunga, S., Ratima, M., Morton, S., Dickson, M., Hsu, D., \& Jackson, R. (2010). Student engagement in very large classes: The teachers' perspective. Studies in Higher Education, 35(7), 761-775.

Farooq, M. S., Chaudhry, A. H., Shafiq, M., \& Berhanu, G. (2011). Factors affecting students' quality of academic performance: A case of secondary school level. Journal of Quality and Technology Management, 7(2), 1-14.

GPE (January 24, 2019). 7 ingredients for a great education. Retrieved from: https://www.globalpartnership.org/blog/7-ingredients-great-education.

Guillén, F., \& Martínez-Alvarado, J. R. (2014). The sport engagement scale: An adaptation of the Utrecht Work Engagement Scale (UWES) for the sports environment. Universitas Psychologica, 13(3), 975-984.

Hagenauer, G., Hascher, T., \& Volet, S. E. (2015). Teacher emotions in the classroom: associations with students' engagement, classroom discipline and the interpersonal teacher-student relationship. European J. of Psychology of Education, 30(4), 385-403.

Hair, J. F., Ringle, C. M., \& Sarstedt, M. (2013). Partial least squares structural equation modeling: Rigorous applications, better results and higher acceptance. Long Range Planning, 46(1-2), 1-12.

Hew, K. F. (2016). Promoting engagement in online courses: What strategies can we learn from three highly rated MOOCS. British J. of Edu. Technology, 47(2), 320-341. 
Hudley, C., Daoud, A., Polanco, T., Wright-Castro, R., \& Hershberg, R. (2003). Student engagement, school climate, and future expectations in high school. Paper presented at the Bicnnial Meeting for the Society of Research in Child Development. Tampa Bay.

Karagiorgi, Y., \& Symeou, L. (2005). Translating constructivism into instructional design: Potential and limitations. J. of Educational Technology \& Society, 8(1), 17-27.

Kezar, A., \& Rhoads, R. A. (2001). The dynamic tensions of service learning in higher education: A philosophical perspective. The J. of Higher Education, 72(2), 148-171.

Lo, J., \& Hyland, F. (2007). Enhancing students' engagement and motivation in writing: The case of primary students in Hong Kong. J. of Second Lang Writing, 16(4), 219-237.

Lohmöller, J. B. (1989). Latent variable path modeling with partial least squares. Springer.

Novo-Corti, I., Badea, L., Tirca, D. M., \& Aceleanu, M. I. (2018). A pilot study on education for sustainable development in the Romanian economic higher education. International Journal of Sustainability in Higher Education, 19(4), 817-838.

Parsons, J., \& Taylor, L. (2011). Improving student engagement. Current Issues in Education, 14(1), 1-32.

Pietarinen, J., Soini, T., \& Pyhältö, K. (2014). Students' emotional and cognitive engagement as the determinants of well-being and achievement in school. International Journal of Educational Research, 67, 40-51.

Pratt, D. D. (2002). Good teaching: One size fits all? New Directions for Adult and Continuing Education, 2002(93), 5-16.

Pratt, D. D., \& Collins, J. B. (2020). Teaching perspectives inventory: The five Perspectives. Retrieved from: http://www.teachingperspectives.com/tpi/

Pratt, D., \& Collins, J. (2002). Summary of five perspectives on good teaching. Retrieved from http://blogs.ubc.ca/srikanth/files/2011/12/TPI-Teaching-PerspectivesSummaries.pdf.

Rachel, M., \& Stefan, T. (2018). Education in Thailand. Retrieved from https://wenr.wes.org/2018/02/education-in-thailand-2.

Reeve, J., \& Shin, S. H. (2019). How teachers can support students' agentic engagement. Theory Into Practice, 59(2), 150-161.

Reeve, J., Jang, H., Carrell, D., Jeon, S., \& Barch, J. (2004). Enhancing students' engagement by increasing teachers' autonomy support. Motiv. and Emo, 28(2), 147-169.

Rivers, W. M. (2018). Teaching foreign language skills. University of Chicago Press.

Robertson, A. C., Fowler, L. C., \& Juve, A. M. (2017). Using the teaching perspectives inventory as an introduction to a residents-as-teachers curriculum. The Journal of Education in Perioperative Medicine: JEPM, 19(4), E614. 
Robinson, J. K. (2013). Project-based learning: improving student engagement and performance in the laboratory. Analytical and Bioanalytical Chemistry, 405(1), 7-13.

Roorda, D. L., Koomen, H. M., Spilt, J. L., \& Oort, F. J. (2011). The influence of affective teacher-student relationships on students' school engagement and achievement: A meta-analytic approach. Review of Edu. Research, 81(4), 493-529.

Sarstedt, M., Hair Jr, J. F., Cheah, J. H., Becker, J. M., \& Ringle, C. M. (2019). How to specify, estimate, and validate higher-order constructs in PLS-SEM. Australasian Marketing Journal (AMJ), 27(3), 197-211.

Sinatra, G. M., Heddy, B. C., \& Lombardi, D. (2015). The challenges of defining and measuring student engagement in science. Educational Psychologist, 50(1), 1-13.

Sulaiman, W. S. W., \& Zahoni, N. A. (2016). Validation of the Utrecht work engagement scale (UWES) in the Malaysian context. Int J of Soc Sci \& Hum., 6(9), 672.

Tai, J. H. M., Bellingham, R., Lang, J., \& Dawson, P. (2019). Student perspectives of engagement in learning in contemporary and digital contexts. Higher Education Research \& Development, 38(5), 1075-1089.

Temple, C. A., Ogle, D., Crawford, A. N., \& Freppon, P. (2017). All children read: Teaching for literacy in today's diverse classrooms. Pearson.

Vollet, J. W., Kindermann, T. A., \& Skinner, E. A. (2017). In peer matters, teachers matter: Peer group influences on students' engagement depend on teacher involvement. Journal of Educational Psychology, 109(5), 635.

Vytasek, J. M., Patzak, A., \& Winne, P. H. (2020). Analytics for student engagement. In G. A. Tsihrinrzis, D. N. Sotriopoulos, \& L. C. Chain (Eds.), Machine learning paradigms (pp. 23-48). Cham: Springer.

Williams, D. G., \& Evans-Winters, V. (2005). The burden of teaching teachers: Memoirs of race discourse in teacher education. The Urban Review, 37(3), 201-219.

Wold, H. (1982). Soft modeling: the basic design and some extensions. Systems Under Indirect Observation, 2, 343.

Woolman, D. C. (2001). Educational reconstruction and post-colonial curriculum development: A comparative study of four African countries. Int. Edu. J., 2(5), 27-46.

Zepke, N., \& Leach, L. (2010). Improving student engagement: Ten proposals for action. Active Learning in Higher Education, 11(3), 167-177. 